\title{
Similarity of the Discriminative Stimulus Effects of Ketamine, Cyclazocine, and Dextrorphan in the Pigeon
}

\author{
Seymore Herling, Edward H. Coale, Jr., David W. Hein, Gail Winger, and James H. Woods \\ Departments of Pharmacology and Psychology, University of Michigan, Ann Arbor, Michigan 48109, USA
}

\begin{abstract}
Separate groups of pigeons were trained to discriminate the IM injection of ketamine, cyclazocine, or dextrorphan from saline. Each of the training drugs and phencyclidine produced dose-related, drug-appropriate responding in each group of birds. In contrast, ethylketazocine and nalorphine generally produced responding appropriate for saline. These results indicate that common elements of discriminable effects exist among ketamine, cyclazocine, and dextrorphan, structurally dissimilar compounds that are generally considered to belong to distinct pharmacological classes.
\end{abstract}

Key words: Phencyclidine - Drug discrimination Ketamine - Pigeons - Dextrorphan - Ethylketazocine Cyclazocine - Nalorphine

The discriminative stimulus effect of a drug is often shared only by compounds that share the drug's other pharmacological actions (Barry 1974; Weissman 1978). For example, when morphine is established as a discriminative stimulus, a variety of narcotic analgesics (e. g., methadone, levorphanol) produce responding appropriate for morphine, while dextrorphan and thebaine, compounds that are structurally related to narcotics but lack many narcotic actions, are without morphine-like discriminative effects (Shannon and Holtzman 1976). Similarly, drugs from several other pharmacological classes - e. g., cannabinoids (Weissman 1978), barbiturates (Colpaert et al. 1976) - appear to produce discriminative stimulus effects that are unique to their own class of drugs.

It has recently been demonstrated in rats that the discriminative stimulus properties of cyclazocine, a narcotic mixed agonist-antagonist, are similar to those of the dissociative anesthetics, ketamine and phencyclidine (Teal and Holtzman 1980). Independently, Shannon (1979) reported that SKF10,047 , the $\mathrm{N}$-allyl-6,7-benzomorphan analogue of cyclazocine, also produced discriminative effects similar to those of phencyclidine in the rat. In squirrel monkeys trained to discriminate cyclazocine from vehicle, dextrorphan and the closely related antitussive, dextromethorphan, produce drugappropriate responding (Wiley and Holtzman 1978). Thus, these pharmacologically dissimilar compounds - i. e., dextrorphan, cyclazocine, and ketamine - appear to share common discriminative stimulus effects. Indeed, Holtzman

Offprint requests to: $\mathrm{S}$. Herling, National Institute on Drug Abuse, Addiction Research Center, P.O. Box 12390, Lexington, KY 40583, USA
(1980) recently demonstrated that dextrorphan, cyclazocine, SKF-10,047, and ketamine resulted in drug-appropriate responding in rats trained to discriminate phencyclidine from saline.

In order to examine the relationships among the interoceptive stimulus effects of these drugs in another species, pigeons were trained to discriminate ketamine, cyclazocine, or dextrorphan from saline, and tests for generalization among these and other compounds were conducted. The spectrum of drug generalization among narcotics in the pigeon appears to be different from that seen in other species (cf. Woods et al. 1980; Herling et al. 1980) and, thus, the pigeon provides an interesting species for comparative studies of the discriminative stimulus properties of drugs. In addition, because the results of tests of stimulus generalization between drugs are not always symmetrical (e. g., Overton and Batta 1979), conclusions about the degree of stimulus similarity among compounds are strengthened when more than one drug is used as the training stimulus.

\section{Materials and Methods}

Subjects. A total of 12 White Carneaux pigeons, obtained from the Veterinary Animal Science Unit, Bowman-Gray Medical School, Winston-Salem, NC, were reduced to approximately $80 \%$ of their free-feeding weights. Sufficient mixed grain and Purina Pigeon Checkers supplemented the mixed grain earned during experimental sessions to maintain these reduced weights. All birds were experimentally-naive and drugnaive prior to the start of this study.

Apparatus. Each experimental chamber had two translucent response keys ( $2 \mathrm{~cm}$ diameter and $5 \mathrm{~cm}$ apart) located $25 \mathrm{~cm}$ above the floor of the chamber and directly above the opening of the food receptacle. Through this opening, mixed grain could be made available from a hopper. A white light illuminated the hopper during food delivery. Each chamber was ventilated by an exhaust fan, and white noise was present to mask extraneous sounds. A more detailed description of the experimental chambers has been reported elsewhere (Herling et al. 1980). Programming, recording, and data collection were accomplished with a Texas Instruments $960 \mathrm{~A}$ computer and cumulative recorders (model C: Ralph Gerbrands Co., Arlington MA).

Procedure. Each pigeon was trained to peck at one of two keys by reinforcing successive approximations of the actual key-peck response with $4 \mathrm{~s}$ access to mixed grain. Following the acquisition of the response, the appropriate key to be pecked in order to produce grain access was determined by the injection the pigeon received prior to the session, e.g., drug (left key) or saline (right key). Across sessions, the number of consecutive responses required to produce grain was increased to 20 . Inappropriate key responses reset the number requirement on the appropriate key. Sessions ended after 32 grain deliveries or $1 \mathrm{~h}$, whichever occurred first. 
Training sessions were usually conducted six days per week. Drug discriminations were established with either cyclazocine $(1.8 \mathrm{mg} / \mathrm{kg}$ in three pigeons), dextrorphan ( $10 \mathrm{mg} / \mathrm{kg}$ in four pigeons, or $17.8 \mathrm{mg} / \mathrm{kg}$ in two pigeons) or ketamine $(5 \mathrm{mg} / \mathrm{kg}$ in one pigeon, or $10 \mathrm{mg} / \mathrm{kg}$ in two pigeons). In each bird, training was initiated and the discrimination sometimes established with the lower of the drug doses, but for individual pigeons, the drug dose was increased when the bird failed to meet the training criteria consistently.

Training continued until each pigeon met the criteria of emitting fewer than 40 responses before the first grain presentation of the session and of distributing at least $90 \%$ of the total session responses on the appropriate key. Each bird was required to meet these criteria for five consecutive sessions during which saline and drug injections alternated, and then on four consecutive sessions prior to which drug or saline was administered in a double alternation sequence (e.g., saline, saline, cyclazocine, cyclazocine).

Once these criteria were met, test sessions were conducted with a range of doses of each of the training drugs, as well as with phencyclidine, nalorphine, and ethylketazocine. Throughout a test session, 20 consecutive responses on either the drug-appropriate or saline-appropriate key produced access to grain; in all other respects, test sessions were identical to training sessions. In general, test sessions alternated during the week with training sessions. If during a training session an animal failed to meet the training criteria, further testing was postponed until the criteria were met on at least two consecutive training sessions. The order of drug administration and the dose sequence were irregular. A more detailed account of the procedure used in this experiment has previously been reported (Herling et al. 1980).

Data Analysis. Data for test sessions are presented as the average number of responses throughout the session that were distributed on the drugappropriate key, expressed as a percentage of the total emitted responses In addition, the overall rate of key-peck responding after drug injection is presented as a percentage of the saline control rate. Saline control response rates were taken from saline training sessions within each drug series.

Drugs. Dextrorphan tartrate (supplied by Dr. W. E. Scott, Hoffmann-La Roche, Nutley, NJ), ketamine hydrochloride (provided by Dr. D. A. Downs, Warner-Lambert/Parke-Davis, Ann Arbor, MI), phencyclidine hydrochloride (supplied by Dr. R. Willette, NIDA, Rockville, MD), and nalorphine hydrochloride (provided by Dr. R. J. Hosley, Eli Lilly, Indianapolis, IN) were dissolved in $0.9 \%$ sterile saline. Ethylketazocine methane sulfonate and cyclazocine base (provided by Dr. W. Michne, Sterling-Winthrop, Rensselaer, NY) were dissolved in sterile water to which a small amount of lactic acid was added; sodium hydroxide was then used to adjust the $\mathrm{pH}$ of these solutions to above 4. Drug doses refer to the forms described. Injections of all drugs and saline were made into the pectoral muscle, usually in a volume of $1 \mathrm{ml} / \mathrm{kg}$, $10 \mathrm{~min}$ prior to the start of the session.

\section{Results}

Each of the pigeons acquired the drug-saline discrimination. The number of sessions required to meet the training criteria ranged in individual birds from 31 to 41 for the cyclazocine group, 36 to 44 for the ketamine group, and 29 to 54 for the dextrorphan group. In general, the differences in training doses used in this experiment resulted in few, if any, differences either in the maintenance of the drug-saline discrimination or in the qualitative nature of the results of subsequent tests of stimulus generalization to other drugs.

Ketamine and phencyclidine produced dose-dependent responding on the drug-appropriate key in each group of pigeons, with phencyclidine being approximately three to ten times more potent than ketamine (Fig. 1, upper panels). Both drugs produced drug-appropriate responding in each group of birds at doses that resulted in an average decrease of less than $40 \%$ of the control response rate (Fig. 1, lower panels).

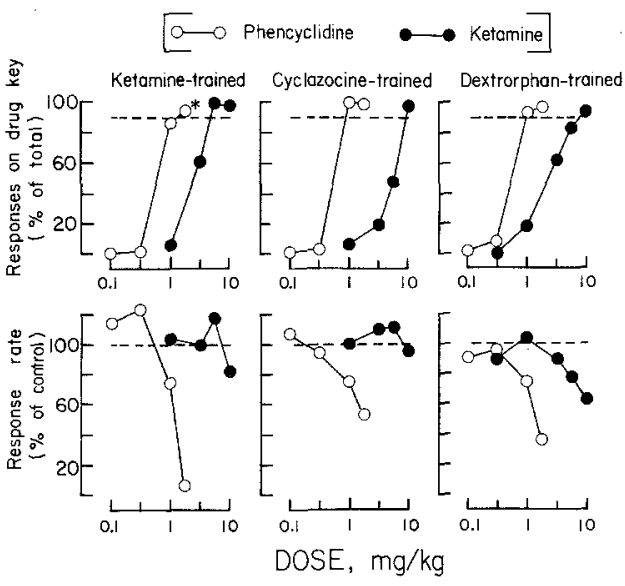

Fig. 1. Discriminative effects of phencyclidine and ketamine in birds trained to discriminate ketamine, cyclazocine, or dextrorphan from saline (upper panels); and the effects of these drugs on the rate of responding (lower panels). The upper panel ordinates indicate the average number of responses emitted on the drug-appropriate key, expressed as a percentage of the total session responses. The lower panel ordinates indicate the average rate of responding following drug injection, expressed as a percentage of the rate of responding on saline training sessions. The abscissae indicate the drug doses in $\mathrm{mg} / \mathrm{kg}$. Each point is the mean of a single observation in each of three birds, except that the effects of ketamine and phencyclidine were determined in only two cyclazocine-trained birds. $*$ One ketamine-trained pigeon did not respond after $1.8 \mathrm{mg} / \mathrm{kg}$ phencyclidine
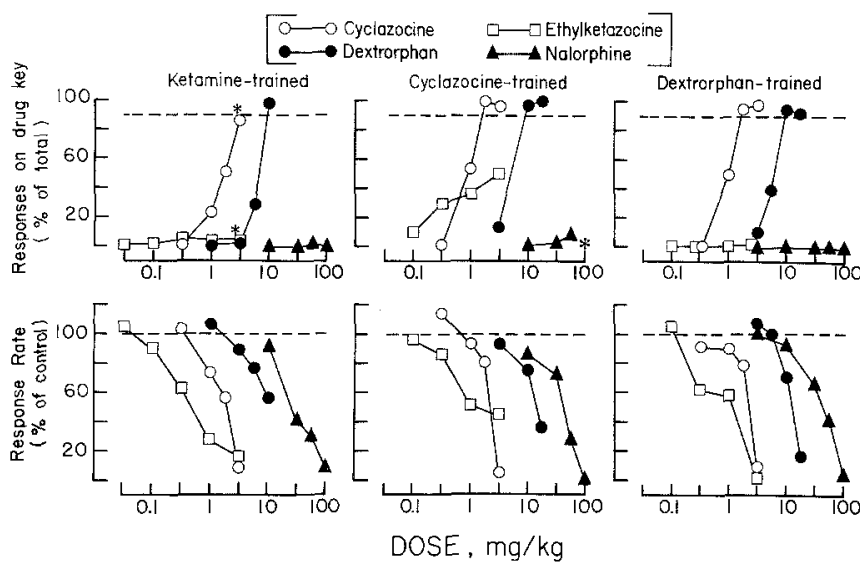

Fig. 2. Discriminative effects of cyclazocine, dextrorphan, ethylketazocine, and nalorphine in pigeons trained to discriminate ketamine, cyclazocine, or dextrorphan from saline (upper panels); and the effects of these drugs on the rate of responding (lower panels). Ordinates and abscissae, as in Fig. 1. Each point is the mean of a single observation in each of three birds, except that effects of dextrorphan were determined in six dextrorphan-trained birds, the highest dose of dextrorphan $(17.8 \mathrm{mg} / \mathrm{kg})$ was administered to only five dextrorphan-trained birds, and the highest dose of nalorphine $(100 \mathrm{mg} / \mathrm{kg})$ was assessed in only two ketamine-trained birds. *One ketamine-trained bird did not respond following $3.2 \mathrm{mg} / \mathrm{kg}$ cyclazocine and a different ketamine-trained bird did not respond after $3.2 \mathrm{mg} / \mathrm{kg}$ ethylketazocine. No cyclazocine-trained bird responded $100 \mathrm{mg} / \mathrm{kg}$ nalorphine. One cyclazocine-trained bird (1002) died after the administration of this dose of nalorphine

Cyclazocine and dextrorphan also produced dose-related, drug-appropriate responding in each group of pigeons (Fig. 2). Cyclazocine was three to five times more potent than dextrorphan in producing drug-appropriate responses (Fig. 2, upper panels) and in reducing response rates (Fig. 2, lower panels). In each group of birds, drug-appropriate 
Table 1. Discriminative effects of drugs in individual birds trained to discriminate ketamine from saline

\begin{tabular}{|c|c|c|c|c|c|c|c|}
\hline \multirow[t]{3}{*}{ Test drug } & \multirow{3}{*}{$\begin{array}{l}\text { Dose } \\
(\mathrm{mg} / \mathrm{kg})\end{array}$} & \multicolumn{6}{|c|}{ Pigeon No. } \\
\hline & & \multicolumn{2}{|l|}{$\begin{array}{l}947 \\
(5 \mathrm{mg} / \mathrm{kg})^{\mathrm{a}}\end{array}$} & \multicolumn{2}{|c|}{$\begin{array}{l}1097 \\
(10 \mathrm{mg} / \mathrm{kg})\end{array}$} & \multicolumn{2}{|c|}{$\begin{array}{l}1155 \\
(10 \mathrm{mg} / \mathrm{kg})\end{array}$} \\
\hline & & $\%$ Drug $^{b}$ & Rate $^{\mathrm{c}}$ & $\%$ Drug & Rate & $\%$ Drug & Rate \\
\hline \multirow[t]{2}{*}{ Phencyclidine } & 0.1 & 0 & 126 & 0 & 123 & 0 & 91 \\
\hline & 1.8 & $* \mathrm{~d}$ & 0 & 91 & 7 & 94 & 5 \\
\hline \multirow[t]{4}{*}{ Ketamine } & 1.0 & 1 & 100 & 3 & 96 & 10 & 114 \\
\hline & 3.2 & 85 & 92 & 13 & 75 & 83 & 129 \\
\hline & 5.6 & 100 & 100 & 97 & 118 & 100 & 134 \\
\hline & 10.0 & 100 & 66 & 99 & 90 & 92 & 86 \\
\hline \multirow[t]{4}{*}{ Dextrorphan } & 1.0 & 3 & 133 & 0 & 88 & 0 & 100 \\
\hline & 3.2 & 7 & 60 & 8 & 103 & 1 & 104 \\
\hline & 5.6 & 69 & 31 & 14 & 94 & 0 & 102 \\
\hline & 10.0 & 100 & 9 & 97 & 81 & 94 & 79 \\
\hline \multirow[t]{5}{*}{ Ethylketazocine } & 0.03 & 0 & 111 & 1 & 95 & 0 & 106 \\
\hline & 0.1 & 0 & 83 & 1 & 95 & 6 & 92 \\
\hline & 0.3 & 0 & 51 & 2 & 62 & 6 & 77 \\
\hline & 1.0 & 2 & 37 & 11 & 42 & 0 & 6 \\
\hline & 3.2 & 1 & 40 & 4 & 9 & $*$ & 0 \\
\hline \multirow[t]{3}{*}{ Nalorphine } & 10.0 & 0 & 51 & 0 & 127 & 0 & 99 \\
\hline & 32.0 & 0 & 12 & 1 & 34 & 0 & 78 \\
\hline & 56.0 & 3 & 7 & 1 & 49 & 0 & 37 \\
\hline
\end{tabular}

a Given in parentheses under each pigeon's number is the training dose for that pigeon

b Each entry is the percentage of total respones during the session that occurred on the drug-appropriate key

c Each entry is the rate of key-peck responding after drug injection, expressed as a percentage of the saline control rate

d Asterisks indicate that no responding occurred during the session

responding occurred at doses of cyclazocine and dextrorphan that usually produced an average rate suppression of between 20 and $40 \%$ of the control rate of responding. In contrast to the effects of phencyclidine and each of the training drugs, ethylketazocine and nalorphine, at doses up to and including those that markedly suppressed response rates, resulted in responding that was generally restricted to the salineappropriate key (Fig. 2).

The performances of individual pigeons, some of which were trained with different training doses, are shown in Tables $1-3$. Of the three ketamine-trained pigeons (Table 1), two were trained with $10 \mathrm{mg} / \mathrm{kg}$ (1097 and 1155) and one with $5 \mathrm{mg} / \mathrm{kg}(947)$ of ketamine. The one bird trained with the lower of the ketamine doses (947) was somewhat more sensitive to the discriminative stimulus and rate-decreasing effects of phencyclidine, cyclazocine, and dextrorphan, but not ketamine, than the two birds trained at the higher ketamine dose (Table 1).

In the dextrorphan-trained group (Table 2), birds were trained with either 10 or $17.8 \mathrm{mg} / \mathrm{kg}$ dextrorphan. One bird trained with the higher of the dextrorphan doses (898) was slightly less.sensitive to the discriminative effects of ketamine than birds trained at the lower dextrorphan dose. In this bird, more than $90 \%$ drug-appropriate responding $(91 \%)$ occurred only after $17.8 \mathrm{mg} / \mathrm{kg}$ of ketamine, a dose of the drug that reduced rate of responding to $22 \%$ of the control rate. The difference in the training doses of dextrorphan, however, did not appear to affect differentially the response of these birds to cyclazocine or dextrorphan.

Likewise, differences in the training doses of ketamine (Table 1) or dextrorphan (Table 2) did not affect the distribution of responses in these birds following injections of ethylketazocine or nalorphine. In contrast, the birds trained with a single dose of cyclazocine $(1.8 \mathrm{mg} / \mathrm{kg}$; Table 3$)$ showed marked individual differences in their response to ethylketazocine, but not to nalorphine. Ethylketazocine produced predominantly saline-appropriate responding in one cyclazocine-trained bird (708), responding intermediate between that appropriate for cyclazocine or saline in a second bird (869), and a dose-dependent drug-appropriate response in a third (1002).

\section{Discussion}

The findings of the present experiment demonstrate that common components of the discriminable effects exist among phencyclidine, ketamine, cyclazocine, and dextrorphan. While it is unlikely that these drugs are identical in all their actions, some elements among a complex set of stimuli may be shared. For example, ethylketazocine produced varying 
Table 2. Discriminative effects of drugs in individual birds trained to discriminate dextrorphan from saline

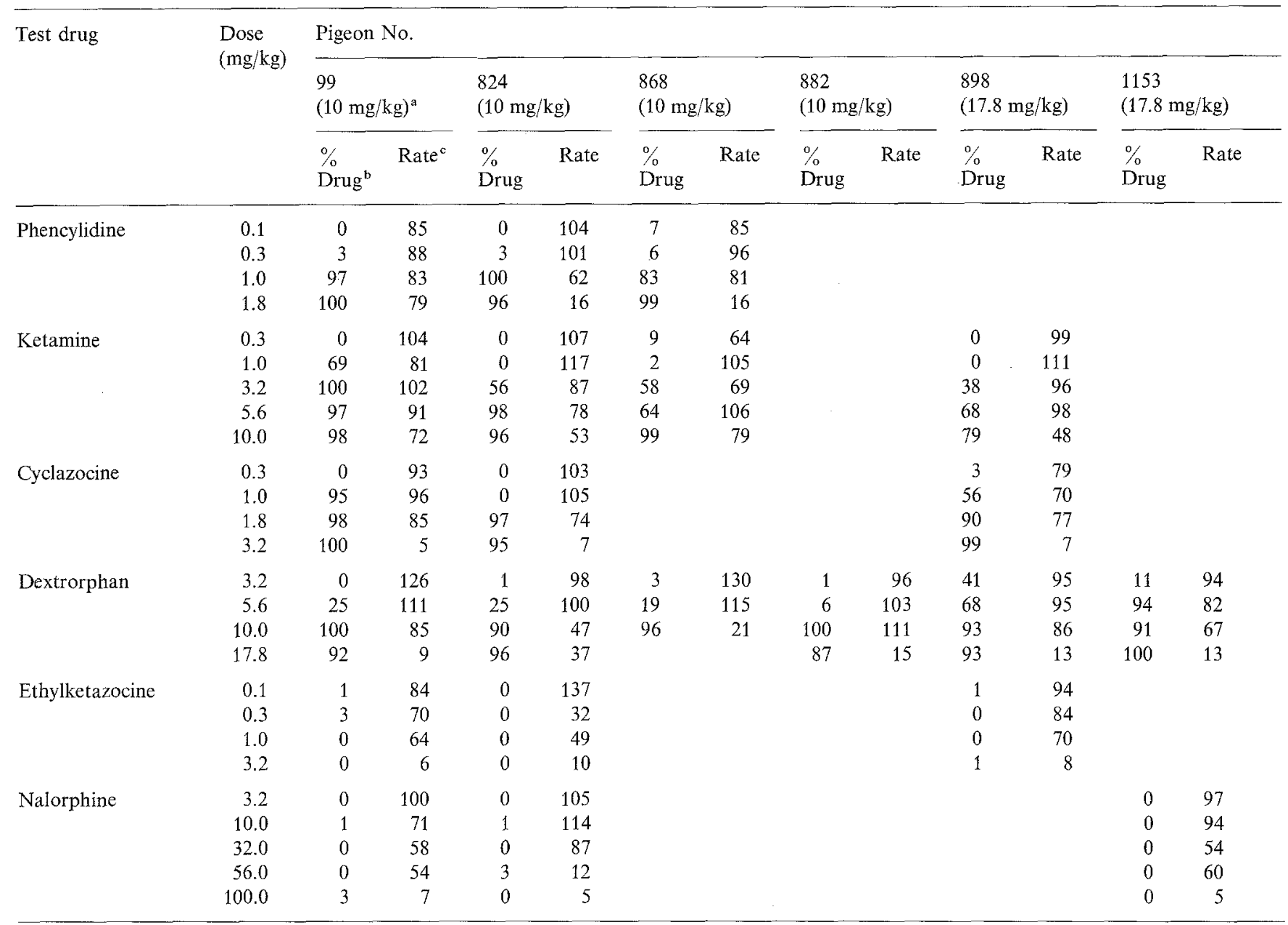

a, $\mathbf{b}, \mathbf{c}$ Footnotes as in Table 1

amounts of drug-appropriate responding in the cyclazocinetrained pigeons, but only saline-appropriate responding in the birds of the other two groups, suggesting that ethylketazocine and cyclazocine may share stimulus properties that are unlike those of either ketamine or dextrorphan.

These results in the pigeon corroborate the findings of a number of other investigators who have recently noted similarities among the discriminative stimulus effects of phencyclidine, ketamine, cyclazocine, and dextrorphan in other species. In rats trained to discriminate phencyclidine from saline, for example, ketamine, cyclazocine, and dextrorphan produce phencyclidine-appropriate responding (Shannon 1979; Holtzman 1980). Similarly, rats trained to discriminate cyclazocine from saline generalize to ketamine and phencyclidine (Teal and Holtzman 1980), and squirrel monkeys trained to discriminate between saline and cyclazocine generalize to dextrorphan (Wiley and Holtzman 1978). The relative potencies of these drugs in producing discriminative effects in the pigeon are similar to those seen in rats. Phencyclidine is slightly more potent than cyclazocine, and approximately ten to 15 times more potent than dextrorphan (cf. Figs. 1 and 2; Holtzman 1980). In agreement with the findings of several others in rats, phencyclidine is three to ten times more potent than ketamine in the pigeon (cf. Fig. 1; Overton 1975; Poling et al. 1979; Holtzman 1980).
The present findings in pigeons and those of others in rats (e. g., Shannon 1979; Teal and Holtzman 1980; Holtzman 1980) also point to differences between narcotics that share discriminative effects with ketamine or phencyclidine (e. g., cyclazocine) and narcotics such as ethylketazocine and nalorphine. Ethylketazocine produces discriminative effects in the pigeon that are similar to those of morphine (Herling et al. 1980). Conversely, neither ethylketazocine (Fig. 2) nor morphine (S. Herling, unpublished observations) produces responding appropriate for ketamine or dextrorphan. Holtzman (1980) has proposed that in the rat certain opioids, including cyclazocine and dextrorphan, share with phencyclidine a common component of action that is mediated by neuronal substrates not usually associated with opiate activity. Phencyclidine-appropriate responding engendered by cyclazocine in rats, for example, is unaffected by $1.0 \mathrm{mg} / \mathrm{kg}$ naltrexone (Holtzman 1980). In pigeons, as well, the discriminative effects of cyclazocine, dextrorphan, and ketamine are not blocked by doses of naltrexone as high as $10 \mathrm{mg} / \mathrm{kg}$ (S. Herling, unpublished observations). Thus, the nature of the phencyclidine, ketamine, cyclazocine, or dextrorphan discriminative stimulus appears to have little in common with that of morphine-like narcotics.

In the chronic spinal dog, one can also differentiate the profile of phencyclidine's pharmacologic effects (Vaupel and 
Table 3. Discriminative effects of drugs in individual birds trained to discriminate cyclazocine from saline

\begin{tabular}{|c|c|c|c|c|c|c|c|}
\hline \multirow[t]{3}{*}{ Test drug } & \multirow{3}{*}{$\begin{array}{l}\text { Dose } \\
(\mathrm{mg} / \mathrm{kg})\end{array}$} & \multicolumn{6}{|c|}{ Pigeon No. } \\
\hline & & \multicolumn{2}{|c|}{$\begin{array}{l}708 \\
(1.8 \mathrm{mg} / \mathrm{kg})^{\mathrm{a}}\end{array}$} & \multicolumn{2}{|c|}{$\begin{array}{l}869 \\
(1.8 \mathrm{mg} / \mathrm{kg})\end{array}$} & \multicolumn{2}{|c|}{$\begin{array}{l}1002 \\
(1.8 \mathrm{mg} / \mathrm{kg})\end{array}$} \\
\hline & & $\%$ Drug $^{\mathrm{b}}$ & Rate $^{\mathrm{c}}$ & $\%$ Drug & Rate & $\%$ Drug & Rate \\
\hline \multirow[t]{2}{*}{ Phencyclidine } & 0.1 & 0 & 113 & 0 & 101 & & \\
\hline & 1.8 & 98 & 30 & 100 & 75 & & \\
\hline \multirow[t]{4}{*}{ Ketamine } & 1.0 & 1 & 111 & 10 & 89 & & \\
\hline & 3.2 & 2 & 123 & 55 & 95 & & \\
\hline & 5.6 & 1 & 116 & 94 & 106 & & \\
\hline & 10.0 & 94 & 111 & 100 & 79 & & \\
\hline \multirow[t]{3}{*}{ Dextrorphan } & 3.2 & 6 & 88 & 28 & 106 & 6 & 83 \\
\hline & 10.0 & 97 & 67 & 100 & 108 & 95 & 50 \\
\hline & 17.8 & 100 & 25 & 100 & 73 & 100 & 8 \\
\hline \multirow[t]{5}{*}{ Ethylketazocine } & 0.1 & 0 & 99 & 0 & 93 & 29 & 96 \\
\hline & 0.3 & 6 & 86 & 0 & 105 & 84 & 68 \\
\hline & 1.0 & 19 & 64 & 3 & 73 & 89 & 26 \\
\hline & 3.2 & 5 & 37 & 48 & 84 & 100 & 15 \\
\hline & 10.0 & $* d$ & 0 & 60 & 58 & & \\
\hline \multirow[t]{4}{*}{ Nalorphine } & 10.0 & 0 & 88 & 0 & 107 & 2 & 65 \\
\hline & 32.0 & 3 & 87 & 10 & 65 & 0 & 66 \\
\hline & 56.0 & 0 & 57 & 27 & 28 & 1 & 36 \\
\hline & 100.0 & * & 0 & * & 0 & $*$ & 0 \\
\hline
\end{tabular}

$a, b, c, d$ Footnotes as in Table 1

Jasinski 1979; Jasinski et al. 1981) from that produced by morphine (e.g., Martin et al. 1978), and from the effects produced by stimulants (Vaupel et al. 1978), barbiturates (Gilbert and Martin 1977), LSD, and THC (Vaupel and Jasinski 1979). In contrast, SKF-10,047 produces many acute effects in the chronic spinal dog that resembie those of phencyclidine, and cyclazocine shares a number of actions in this preparation with both compounds (cf. Martin et al. 1976; Gilbert and Martin 1976; Vaupel and Jasinski 1979; Jasinski et al. 1981). In man, the subjective effects of cyclazocine and SKF-10,047 are distinguishable from those of morphine but have some aspects in common with phencyclidine and ketamine. These include sedation, disorientation, drunkenness, and psychotomimetic symptomology (cf. Keats and Telford 1964; Domino 1964; Domino et al. 1965; Haertzen 1974). Dextrorphan and its chemical congener, dextromethorphan, also produce subjective and physiologic effects in man that are distinguishable from those of morphine (Isbell and Fraser 1953; Jasinski et al. 1971), and large doses of dextromethorphan engender sedative-hypnotic effects and sensory disturbances that closely resemble subjective effects produced by cyclazocine (Jasinski et al. 1971).

Several investigators have suggested that the discriminative stimulus effects of drugs are analogous to the subjective effects of the drugs in man (e. g., Holtzman et al. 1977; Colpaert 1978). Teal and Holtzman (1980) have proposed that the similarity of the discriminative effects of cyclazocine, phencyclidine, and ketamine in the rat may be related to the psychotomimetic effects that these drugs produce in man. The results of the present study are consistent with this hypothesis. Cyclazocine, ketamine, phencyclidine, and dextrorphan produced similar discriminative effects in the pigeon. Of these drugs, those that been evaluated in man appear to produce remarkably similar subjective effects. It may be, then, as in rats, that the discriminative stimulus effects of cyclazocine, ketamine, phencyclidine, and dextrorphan in pigeons are related to psychotomimetic and sedative-hypnotic effects that are produced by some of these drugs in man.

Acknowledgements. This research was supported by USPHS grants DA 00154 and DA 02230 . D. W. Hein was supported as a predoctoral fellow by NIGMS grant T $32 \mathrm{GM} 07767$. The assistance of Kari L. George in conducting this experiment and the editoral advice of Dr. Alice $\mathrm{M}$. Young are greatly appreciated. We gratefully acknowledge the assistance of Elaine Sudman in preparing the manuscript. A preliminary report of this experiment was presented to the Federation of American Societies for Experimental Biology, Anaheim, Calif., April, 1980 (Fed Proc $39: 994,1980$ ).

\section{References}

Barry H III (1974) Classification of drugs according to their discriminable effects in rats. Fed Proc 33:1814-1824

Colpaert FC (1978) Discriminative stimulus properties of narcotic analgesic drugs. Pharmacol Biochem Behav 9:863-887 
Colpaert FC, Desmedt LKC, Janssen PAJ (1976) Discriminative stimulus properties of benzodiazepines, barbiturates, and pharmacologically related drugs; relation to some intrinsic and anticonvulsant effects. Eur J Pharmacol 37:133-123

Domino EF (1964) Neurobiology of phencyclidine (Sernyl), a drug with an unusual spectrum of pharmacological activity. Int Rev Neurobiol $6: 303-347$

Domino EF, Chodoff P, Corssen GL (1965) Pharmacologic effects of CI581, a new dissociative anesthetic in man. Clin Pharmacol Ther $6: 279-291$

Gilbert PE, Martin WR (1976) The effects of morphine- and nalorphinelike drugs in the nondependent, morphine-dependent and cyclazocine-dependent chronic spinal dog. J Pharmacol Exp Ther $198: 66-82$

Gilbert PE, Martin WR (1977) Antagonism of the effects of pentobarbital in the chronic spinal dog by naltrexone. Life Sci 20:1401-1406

Haertzen CA (1974) Subjective effects of narcotic antagonists. In: Braude MC, Harris LS, May EL, Smith JP, Villarreal JE (eds) Narcotic antagonists, Raven Press, New York, pp 383-398

Herling S, Coale EH Jr, Valentino RJ, Hein DW, Woods JH (1980) Narcotic discrimination in pigeons. J Pharmacol Exp Ther 214:139-146

Holtzman SG (1980) Phencyclidine-like discriminative effects of opioids in the rat. J Pharmacol Exp Ther 214:614-619

Holtzman SG, Shannon HE, Schaefer GJ (1977) Discriminative properties of narcotic antagonists. In: Lal H (ed) Discriminative stimulus properties of drugs, Plenum Press, New York, pp 47-72

Isbell H, Fraser HF (1953) Actions and addiction liabilities of Dromoran derivatives in man. J Pharmacol Exp Ther 107:524-530

Jasinski DR, Martin WR, Mansky PA Progess report on the assessment of the antagonists nalbuphine and GPA-2087 for abuse potential and studies of the effects of dextromethorphan in man. Reported to the 33rd Meeting, Committee on Problems of Drug Dependence, Toronto, Canada 1971. National Academy of Sciences/National Research Council, pp 143-178

Jasinski DR, Shannon HE, Cone EJ, Vaupel DB, Risner ME., McQuinn RL, Su TP, Pickworth WB (1981) Interdisciplinary studies on phencyclidine. In: Domino EF (ed) PCP (Phencyclidine): Historical and current perspectives, NPP Books, Ann Arbor (in press)

Keats AS, Telford J (1964) Narcotic antagonists as analgesics: Clinical aspects. In: Gould RF (ed) Molecular modification in drug design (Advances in Chemistry, Series 45), American Chemical Society, Washington, pp $170-176$
Martin WR, Eades CG, Thompson JA, Huppler RE, Gilbert PE (1976) The effects of morphine- and nalorphine-like drugs in the nondependent and morphine-dependent chronic spinal dog. J Pharmacol Exp Ther 197:517-532

Martin WR, Gilbert PE, Thompson JA, Jessee CA (1978) Use of the chronic spinal dog for the assessment of the abuse potentiality and utility of narcotic analgesics and narcotic antagonists. Drug Alcohol Depend 3:23-34

Overton DA (1975) A comparison of the discriminable CNS effects of ketamine, phencyclidine and pentobarbital. Arch Int Pharmacodyn $215: 180-189$

Overton DA, Batta SK (1979) Investigation of narcotics and antitussives using drug discrimination techniques. J Pharmacol Exp Ther $211: 401-408$

Poling AD, White FJ, Appel JB (1979) Discriminative stimulus properties of phencyclidine. Neuropharmacology 18:459-463

Shannon HE (1979) Evalution of phencyclidine analogs on the basis of their discriminative stimulus properties in the rat. Fed Proc 38:435

Shannon HE, Holtzman SG (1976) Evalution of the discriminative effects of morphine in the rat. J Pharmacol Exp Ther 198:54-65

Teal JJ, Holtzman SG (1980) Discriminative stimulus effects of cyclazocine in the rat. J Pharmacol Exp Ther 212:368-376

Vaupel DB, Jasinski DR (1979) Acute single dose effects of phencyclidine $(\mathrm{PCP})$ in the dog. Fed Proc $38: 435$

Vaupel DB, Nozaki M, Martin WR, Bright LD (1978) Single dose and cross tolerance studies of $\beta$-phenethylamine, $d$-amphetamine and LSD in the chronic spinal dog. Eur I Pharmacol 48:431-437

Weissman A (1978) Generalization of the discriminative stimulus properties of $\Delta^{9}$-tetrahydocannabinol to cannabinoids of therapeutic potential. In: Colpaert FC, Rosecrans JA (eds) Stimulus properties of drugs: Ten years of progress, Elsevier/North Holland Biomedical Press, Amsterdam, pp 99-122

Wiley JT, Holtzman SG (1978) Discriminative effects of dextromethorphan and dextrorphan in the squirrel monkey. Fed Proc 37:322

Woods JH, Herling S, Valentino RJ, Hein DW, Coale EH, Jr.(1980) Narcotic drug discriminations by rhesus monkeys and pigeons. In: Harris LS (ed) Problems of drug dependence, 1979: Proceedings of the 41st annual scientific meeting, The Committee on Problems of Drug Dependence (NIDA Research Monograph 27) U. S. Government Printing Office, Washington, pp 128-134

Received March 18, 1980; Final version January 5, 1981 